\title{
The difference in patterns of motor and cognitive function in chronic fatigue syndrome and severe depressive illness
}

\author{
S. M. LAWRIE, ${ }^{1}$ S. M. MACHALE, J. T. O. CAVANAGH, R. E. O'CARROLL \\ AND G. M. GOODWIN \\ From the Department of Psychiatry, University of Edinburgh; Department of Psychology, University of \\ Stirling; and University Department of Psychiatry, Warneford Hospital, Oxford
}

\begin{abstract}
Background. Chronic fatigue syndrome (CFS) and major depressive disorder (MDD) share many symptoms and aetiological factors but may have different neurobiological underpinnings. We wished to determine the profile of the biological variables disturbed in CFS and MDD, and identify any critical factors that differentiate the disorders.
\end{abstract}

Methods. Thirty patients with CFS, 20 with MDD and 15 healthy controls - matched group-wise for age and sex - were recruited. Subjects were given a detailed battery of motor and cognitive tests, including measures of psychomotor speed, memory and maximal voluntary muscle contraction in both the morning and evening that were balanced to avoid order effects.

Results. CFS patients generally performed worse on cognitive tests than healthy controls, but better than patients with MDD. Both patient groups had markedly impaired motor function compared with healthy controls. MDD subjects showed a significantly greater diurnal improvement in maximal voluntary contraction than healthy controls.

Conclusions. Patients with CFS and MDD show similarly substantial motor impairment, but cognitive deficits are generally more marked in MDD. Diurnal changes in some functions in MDD may differentiate the disorder from CFS.

\section{INTRODUCTION}

The nature of chronic fatigue syndrome (CFS) or 'myalgic encephalomyelitis' (ME) remains controversial. Some clinicians and most patients stress that these conditions are primarily postinfectious and that any emotional disturbance is secondary (Behan \& Bakheit, 1991). However, $50-70 \%$ of CFS sufferers satisfy criteria for psychiatric disorders, particularly depression, which cannot simply be attributed to the effects of prolonged disability (David, 1991; Kendal, 1991). It follows that CFS may share essential aetiological features with mood disorder. Indeed, it may best be thought of as a syndrome

1 Address for correspondence: Dr Stephen M. Lawrie, University of Edinburgh, Department of Psychiatry, Royal Edinburgh Hospital, Edinburgh EH10 5HF. characterized by both fatigue and psychiatric morbidity, triggered by physical and psychosocial stressors, and maintained by biological and psychological factors (Lawrie et al. 1997a). Depressive disorder could be described similarly (Kendal, 1991). It is, therefore, important to measure the quantitative similarities and differences between the two disorders.

The present study extends the parallel understanding of CFS and major depressive disorder (MDD) by a detailed investigation of neurobiological indices. There are preliminary studies of motor and cognitive function in CFS and MDD (which form the basis for hypotheses we examined here) but none is definitive and few bring together more than a single domain of investigation. For example, patients with CFS report an increased perception of muscular effort despite submaximal performance on exercise 
testing (Stokes et al. 1988; Riley et al. 1990), but the same may be true in depression, where impairment of motor function extends even to maximal voluntary hand grip (Cohen et al. 1982; Moffoot et al. 1994). Subjective reports of cognitive impairment in CFS are supported by objective evidence for slowed reaction time and poor memory or attention (Millon et al. 1989; Altay et al. 1990; Riccio et al. 1992; Grafman et al. 1993; MacDonald et al. 1993; Ray et al. 1993; Sandman et al. 1993; Schmaling et al. 1994; Cope et al. 1995; DeLuca et al. 1995; Joyce et al. 1996; Marcel et al. 1996; Marshall et al. 1997; Vollmer-Conna et al. 1997; Wearden \& Appleby, 1997; Johnson et al. 1998). A comparison with depression suggests a similar pattern of impairments (e.g. Austin et al. 1992). However, both motor and cognitive impairments tend to be maximal in the morning and improve over the day in depression (Moffoot et al. 1994; Porterfield et al. 1997). By contrast, CFS patients generally report that symptoms worsen in the evening, although there is little objective data on this point.

We have examined a group of CFS patients with measures of isometric strength, subjective effort, mood and an appropriate series of neuropsychological tests, in the morning and evening, and compared them with groups of both depressed and healthy controls. We also measured endocrine function and cerebral perfusion, but provide accounts of these investigations elsewhere (MacHale et al. 1998, 2000). We specifically tested the hypothesis that the cognitive and motor impairments in depression and CFS would be expressed similarly as reductions in performance as compared to healthy controls, but with diurnal improvement in depression and evening worsening in CFS.

\section{METHOD}

Approval for the project was obtained from the appropriate Ethics Committee.

\section{Subjects}

Thirty patients satisfying operationalized criteria for CFS (Fukuda et al. 1994) were recruited from the local ME association self-help group $(N=13)$ and from the regional infectious diseases unit $(N=17)$. Where possible, patients were selected to be over 30 years of age so that clear evidence of the level of pre-morbid function was obtainable. Sixteen subjects were medication-free at the time of assessment, with the remaining 14 being prescribed either antidepressants (10), hypnotics/anxiolytics (4) and/or endocrine replacement ( 2 on thyroxine, 1 on the oral contraceptive pill). Patients were excluded if there had been any change in their medication in the previous 3 weeks.

Twenty patients with major depression by DSM-III-R criteria (APA, 1987), matched group-wise for age and sex, were recruited from the wards and out-patient services of the Royal Edinburgh Hospital. They were recruited for this study and a within subjects study of diurnal variation in MDD (12 had diurnal variation worst in the morning, eight were worst in the evening) and have not been previously reported. Five MDD patients were medication-free at the time of assessment, with the remaining 15 being prescribed antidepressants (14), hypnotics/ anxiolytics (3), thyroxine (2) and/or lithium (1) in doses which had been stable for at least 3 weeks. A healthy control group of 15 subjects was also recruited, matched for age and sex, from hospital staff and friends of the CFS/ME patients.

All subjects received a standardized psychiatric interview, the Schedule for Affective Disorders and Schizophrenia (SADS) (Endicott \& Spitzer, 1978) to establish any psychiatric diagnosis. Potential CFS/ME subjects with current co-morbid psychiatric disorders, such as depression, were excluded, but those with a previous history of co-morbid depression were not (Fukuda et al. 1994). All subjects also underwent a comprehensive physical examination, and blood screening as thought necessary, to exclude any physical illness that could be responsible for the fatigue or depression. All pre-menopausal female subjects were required to have a negative pregnancy test before inclusion. The severity of depression symptoms were rated using the 17-item Hamilton Depression Rating Scale (HDRS) (Hamilton, 1960). Pre-morbid IQ was assessed with the revised National Adult Reading Test (NART) (Nelson \& Willison, 1991).

The Befindlichskeitskala scale (BFS) (Von Zerssen et al. 1974) was used to measure levels of depression and fatigue in both the morning and evening. This is a self-rating mood scale, with 
Table 1. Clinical characteristics of CFS, MDD and healthy control subjects (CON) (mean (S.D.))

\begin{tabular}{|c|c|c|c|}
\hline & CFS & MDD & $\mathrm{CON}$ \\
\hline Sex (male/female) & $11 / 19$ & $8 / 12$ & $4 / 11$ \\
\hline Age (years) & $44 \cdot 2(10 \cdot 3)$ & $44 \cdot 0(12 \cdot 1)$ & $41 \cdot 1(12 \cdot 8)$ \\
\hline Handedness score & $17 \cdot 6(13 \cdot 3)$ & $14 \cdot 6(14 \cdot 3)$ & $18 \cdot 7(10 \cdot 3)$ \\
\hline Duration of current episode (weeks) & $270 \cdot 1(189 \cdot 2)$ & $44 \cdot 3(61 \cdot 8)$ & - \\
\hline Illness onset age (years) & $38 \cdot 1(10 \cdot 0)$ & $29 \cdot 7(14 \cdot 2)$ & - \\
\hline Likert scoring & $27 \cdot 1(3 \cdot 6)$ & - & - \\
\hline GHQ type scoring & $10 \cdot 4(0 \cdot 9)$ & - & - \\
\hline \multicolumn{4}{|l|}{ SF 36} \\
\hline Health transition & $2 \cdot 9(1 \cdot 1)$ & - & - \\
\hline Bodily pain & $41.9(24 \cdot 4)$ & - & - \\
\hline General health & $31 \cdot 3(18 \cdot 4)$ & - & - \\
\hline Emotional role limitations & $80 \cdot 0(34 \cdot 6)$ & - & - \\
\hline Social functioning & $36 \cdot 2(24 \cdot 4)$ & - & - \\
\hline
\end{tabular}

impressive validity and reliability, in which subjects choose from 28 positive/negative word pairs to describe their state of mind (scoring 2 or 0 respectively, or 1 if undecided, giving a total score range of $0-56$ and a range of $0-16$ for the depression and fatigue items).

In CFS subjects, the severity of fatigue was scored on the Chalder scale (Chalder et al. 1993) while functional impairment was measured with the SF36 (Ware \& Sherbourne, 1992). The SF36 is a validated self-report questionnaire, scaled scores giving levels of current functioning that vary from 0 to $100 \%$ of normal (other than health transition where scores range from $0-5$ with lower numbers reflecting greater improvement over the past year). Demographic data and clinical scores are summarized in Tables 1 and 2 .

\section{Cognitive and motor function assessment}

A comprehensive battery of neuropsychological tests was administered. The CFS and healthy control groups completed the Block Design subtest of the Wechsler Adult Intelligence ScaleRevised (WAIS-R) (Wechsler, 1981), Verbal Fluency (Benton \& Hamsher, 1978), Trails A and B (Reitan, 1958), Paired Associates Learning (PAL) (Wechsler, 1981), the Boston Naming Test (Kaplan et al. 1983), the 2- and 4-second versions of the Paced Auditory Serial Addition Test (PASAT) (Brittain et al. 1981), and the California Verbal Learning Test (CVLT) (Delis et al. 1987).
The CFS and healthy control groups completed a number of tests in both the morning and evening on matched, parallel versions of: digit span forwards and backwards (Randt \& Brown, 1983); reaction time measures from the Cambridge Neuropsychological Test Automated Battery (CANTAB) (Sahakian \& Owen, 1992); and a sustained hand grip test, which required subjects to maintain a hand grip at $10 \mathrm{~kg}$ pressure on a dynamometer, for as long as possible, up to a maximum of $3 \mathrm{~min}$. Immediately after the latter, subjects were asked to complete the Borg effort scale (Borg, 1982).

The remaining cognitive and motor tasks were completed by all subjects in both the morning and evening. The Digit Symbol Substitution Test (DSST) (Wechsler, 1981) was followed by the Auditory Verbal Learning Test, including the delayed recall and recognition sections (AVLT) (Rey, 1964; Lezak, 1983; Crawford et al. 1989). The AVLT is a test of immediate, short- and long-term memory. A 15item list (A) is read aloud to participants who are asked to recall the items immediately and after four consecutive repetitions. A second word list (B) is then presented, which subjects are asked to repeat, before recalling list A again. This first part of the AVLT is usually completed in $15 \mathrm{~min}$. Delayed recall and recognition of list A are then tested after 30 min. Finally, subjects were asked to squeeze a handgrip dynamometer as hard as possible on three occasions in both 
Table 2. BFS symptom ratings (mean (S.D.)) morning and evening in CFS, MDD and healthy control subjects $(C O N)$

\begin{tabular}{|c|c|c|c|c|c|c|}
\hline BFS & & CFS & MDD & $\mathrm{CON}$ & $\begin{array}{c}F \text { value } \\
\text { Group effect } \\
\text { Time effect } \\
\text { Interaction }\end{array}$ & $\begin{array}{c}P \text { value } \\
\text { Group effect } \\
\text { Time effect } \\
\text { Interaction }\end{array}$ \\
\hline Fatigue & $\begin{array}{l}\text { a.m. } \\
\text { p.m. }\end{array}$ & $\begin{array}{l}9 \cdot 6(5 \cdot 3) \\
9 \cdot 7(4 \cdot 8)\end{array}$ & $\begin{array}{r}10 \cdot 2(5 \cdot 9) \\
9 \cdot 2(5 \cdot 1)\end{array}$ & $\begin{array}{l}2 \cdot 5(4 \cdot 6) \\
3 \cdot 5(5 \cdot 1)\end{array}$ & $\begin{array}{c}15 \cdot 7 \\
0 \cdot 01 \\
0 \cdot 4\end{array}$ & $\begin{array}{l}<0.001 * \\
1.0 \\
0.7\end{array}$ \\
\hline Depression & $\begin{array}{l}\text { a.m. } \\
\text { p.m. }\end{array}$ & $\begin{array}{l}3 \cdot 6(3 \cdot 0) \\
3 \cdot 9(3 \cdot 4)\end{array}$ & $\begin{array}{l}9 \cdot 0(5 \cdot 0) \\
8 \cdot 1(5 \cdot 0)\end{array}$ & $\begin{array}{l}1 \cdot 0(1 \cdot 6) \\
1 \cdot 7(2 \cdot 8)\end{array}$ & $\begin{array}{c}24 \cdot 4 \\
0 \cdot 01 \\
0 \cdot 9\end{array}$ & $\begin{aligned}< & 0.001 \dagger \\
& 0.9 \\
& 0.4\end{aligned}$ \\
\hline Total scores & $\begin{array}{l}\text { a.m. } \\
\text { p.m. }\end{array}$ & $\begin{array}{l}21 \cdot 8(12 \cdot 4) \\
22 \cdot 9(11 \cdot 6)\end{array}$ & $\begin{array}{l}38 \cdot 1(14 \cdot 3) \\
38 \cdot 8(12 \cdot 2)\end{array}$ & $\begin{array}{l}6 \cdot 3(6 \cdot 6) \\
8 \cdot 1(8 \cdot 8)\end{array}$ & $\begin{array}{c}48 \cdot 6 \\
0 \cdot 4 \\
0 \cdot 03\end{array}$ & $\begin{array}{c}<0.001+ \\
0.5 \\
1 \cdot 0\end{array}$ \\
\hline
\end{tabular}

* CFS, MDD $>$ CON $(P<0.05)$ both morning and evening.
$\dagger$ MDD $>$ CFS, CON $(P<0.05)$ both morning and evening.

$\$$ MDD $>$ CFS $>$ CON $(P<0.05)$ both morning and evening.

hands (averaged to assess maximum voluntary contraction in each hand).

All the diurnal tests were conducted twice in a balanced design, to avoid order effects. Subjects were randomly allocated to being tested first at 8 a.m. and then 8 p.m. of the same day or 8 p.m. followed by 8 a.m. the next morning. Parallel versions of all the repeated tests were used in the second testing session. The order of particular tests was however the same in both sessions.

\section{Statistical analysis}

Cognitive and motor tests given to only CFS and control subjects were compared by one-way analysis of variance (ANOVA). The clinical ratings (BFS), cognitive and motor tests completed by subjects in both morning and evening were compared by repeated measures ANOVA with an interaction term for the hypothesized group by time effects. Significant group, time or interaction effects were then examined with planned ANOVA and post hoc Scheffé tests to identify the nature of the effects, controlling for multiple comparisons. The analyses were repeated comparing CFS subjects on and off medication.

\section{RESULTS}

\section{Subjects}

As shown in Table 1, the subject groups were well matched for age and pre-morbid IQ, but male healthy controls were under-represented. The CFS subjects had become ill at an older age than the MDD subjects, but their current (and only) episode had been longer. As expected, the levels of depressive symptomatology were higher in MDD subjects than CFS subjects, who in turn had higher levels than the healthy controls. The CFS subjects reported high levels of fatigue and were substantially incapacitated as measured by several ratings on the SF36 - particularly in levels of vitality, physical and social functioning and general health. The mean score of 2.9 on health transition indicates that most CFS subjects had not noted much change in their condition over the previous year.

CFS and MDD subjects scored equally high on the BFS fatigue score, but levels of depression were much higher in MDD than CFS patients (see Table 2). Both CFS and healthy subjects tended to report greater levels of symptoms in the evening than in the morning, with the opposite being true in the MDD subjects, but none of the diurnal changes in symptoms was statistically significant.

\section{Cognition}

Table 3 shows the results from the neuropsychological tests that were given to CFS and healthy controls on only one occasion. The differences were small. The only statistically significant effect is the fewer total number of words produced on the verbal fluency test. However, the CFS subjects consistently do slightly worse than the healthy controls. (They also show a tendency to do relatively worse, as measured by effect sizes, on 'harder' than 'easier' tests - i.e. scoring lower on Trails B than A, lower on PAL hard than easy pairs, and 
Table 3. Neuropsychological test results (mean (S.D.)) in CFS and healthy control subjects $(C O N)$

\begin{tabular}{|c|c|c|c|c|}
\hline & CFS & $\mathrm{CON}$ & $\begin{array}{c}\text { Test statistic } \\
F\end{array}$ & $P$ value (Effect size)* \\
\hline Trails A & $25 \cdot 7(11 \cdot 6)$ & $25 \cdot 3(7 \cdot 0)$ & $0 \cdot 02$ & $0.9(0.03)$ \\
\hline Trails B & $59 \cdot 2(19 \cdot 9)$ & $56 \cdot 3(14 \cdot 8)$ & $0 \cdot 2$ & $0.6(0.19)$ \\
\hline Block design & $12 \cdot 3(3 \cdot 3)$ & $12 \cdot 4(3 \cdot 1)$ & $0 \cdot 01$ & $0.9(0.03)$ \\
\hline Boston naming test & $56 \cdot 8(4 \cdot 2)$ & $55.9(2.9)$ & 0.06 & $0.5(0.31)$ \\
\hline Verbal fluency (all FAS) & $44 \cdot 1(11 \cdot 5)$ & $51 \cdot 7(12 \cdot 3)$ & $4 \cdot 1$ & $0.048(0 \cdot 61)$ \\
\hline \multicolumn{5}{|l|}{ PASAT } \\
\hline $2 \mathrm{~s}$ & $36 \cdot 4(10 \cdot 1)$ & $42 \cdot 7(10 \cdot 4)$ & $3 \cdot 7$ & $0.06(0 \cdot 61)$ \\
\hline $4 \mathrm{~s}$ & $52 \cdot 7(6 \cdot 1)$ & $55 \cdot 3(5 \cdot 6)$ & 1.9 & $0 \cdot 2(0 \cdot 46)$ \\
\hline \multicolumn{5}{|l|}{ Paired associates } \\
\hline Easy & $11 \cdot 2(1 \cdot 2)$ & $11 \cdot 6(0 \cdot 7)$ & 1.6 & $0.2(0.57)$ \\
\hline Hard & $7 \cdot 5(3 \cdot 6)$ & $9 \cdot 4(2 \cdot 5)$ & $3 \cdot 2$ & $0.08(0 \cdot 76)$ \\
\hline \multicolumn{5}{|l|}{ CVLT } \\
\hline $\begin{array}{l}\text { Semantic cluster ratio } \\
\text { (standard score) }\end{array}$ & $0 \cdot 0(1 \cdot 2)$ & $0 \cdot 2(1 \cdot 5)$ & $0 \cdot 2$ & $0 \cdot 6(0 \cdot 13)$ \\
\hline $\begin{array}{l}\text { Serial cluster ratio } \\
\text { (standard score) }\end{array}$ & $-0 \cdot 2(1 \cdot 0)$ & $-0.5(0 \cdot 9)$ & $0 \cdot 6$ & $0.4(0.33)$ \\
\hline $\begin{array}{l}\text { Recognition hits } \\
\text { (standard score) }\end{array}$ & $-0.4(1.5)$ & $0 \cdot 1(1 \cdot 1)$ & $1 \cdot 3$ & $0 \cdot 3(0 \cdot 45)$ \\
\hline $\begin{array}{l}\text { Discriminability } \\
\text { (standard score) }\end{array}$ & $0 \cdot 0(0 \cdot 9)$ & $0 \cdot 4(0 \cdot 6)$ & $2 \cdot 5$ & $0 \cdot 1(0.67)$ \\
\hline $\begin{array}{l}\text { Long } v \text {. short } \\
\text { delay free recall } \\
\text { (difference score) }\end{array}$ & $-0 \cdot 2(0 \cdot 6)$ & $-0.4(1.5)$ & $0 \cdot 7$ & $0 \cdot 4(0 \cdot 13)$ \\
\hline
\end{tabular}

* Effects sizes (in S.D. units) are calculated as the difference in means divided by the standard deviation in controls.

Table 4. Neuropsychological performance, sustained hand grip time and Borg ratings - morning and evening (mean S.D.) - in CFS and healthy control subjects (CON)

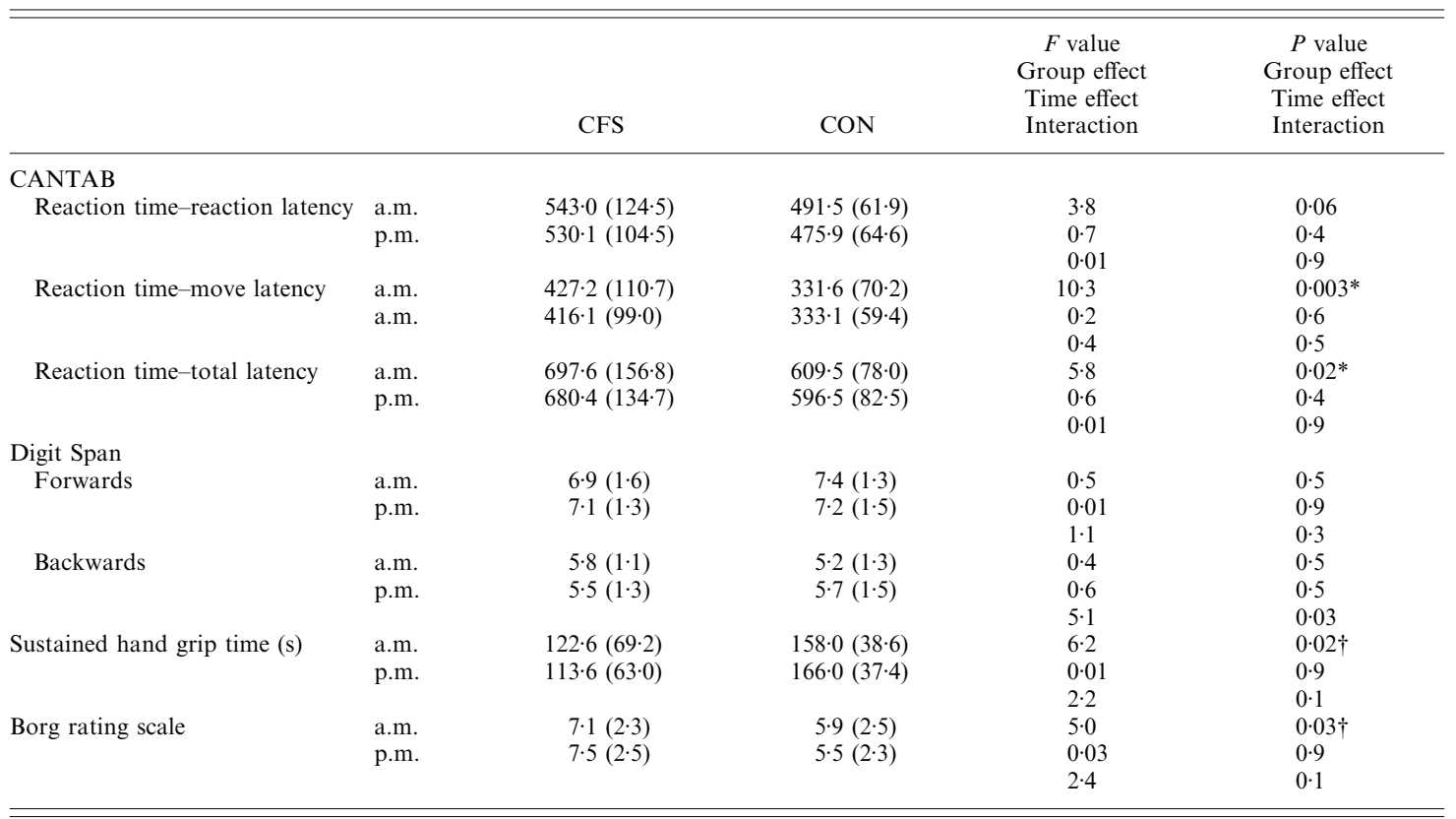

* CFS worse than CON $(P<0 \cdot 05)$ both morning and evening.

$\dagger$ CFS worse than CON $(P<0.05)$ in evening only. 
Table 5. Neuropsychological test results - morning and evening (mean (S.D.)) - in CFS, MDD and healthy control subjects $(\mathrm{CON})$

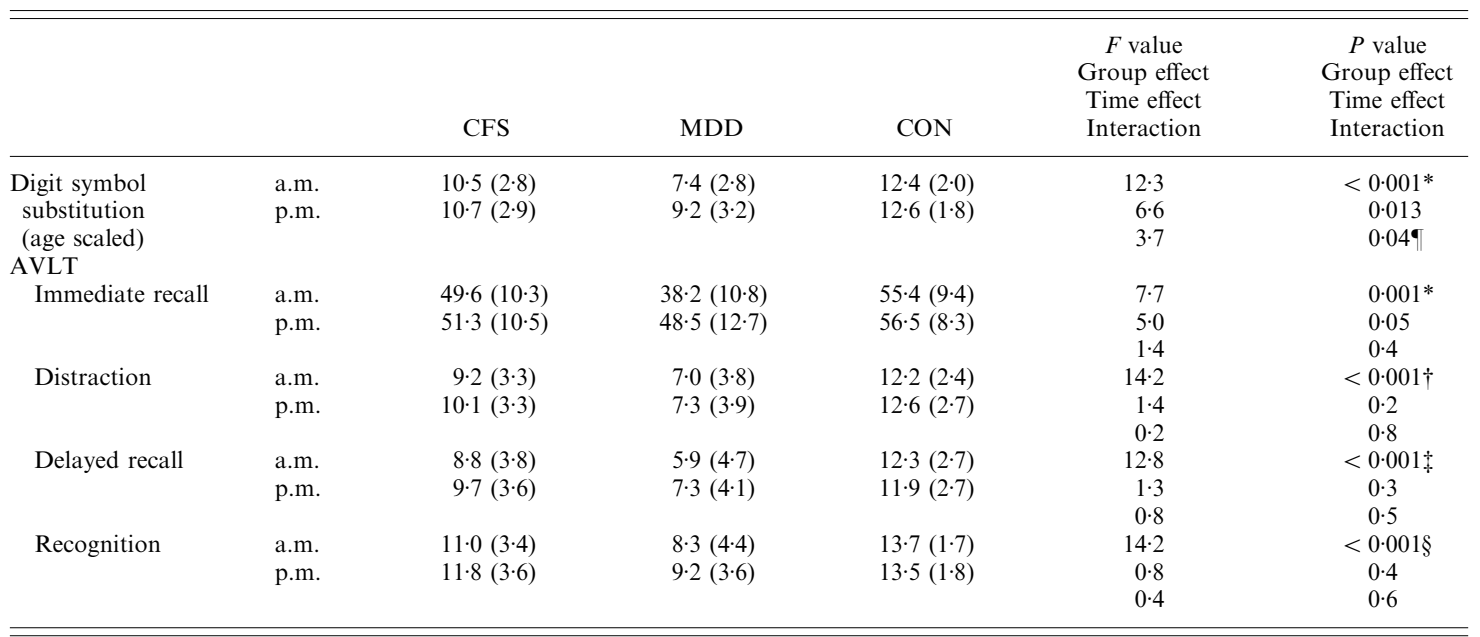

* MDD $<$ CFS, CON $(P<0.05)$ in morning, MDD $<$ CON $(P<0.05)$ in evening.

$\dagger \mathrm{MDD}, \mathrm{CFS}<\mathrm{CON}(P<0.05)$ in morning, MDD $<$ CFS, CON $(P<0.05)$ in evening.

$+\mathrm{MDD}<\mathrm{CFS}<\mathrm{CON}(P<0 \cdot 05)$ in morning, MDD $<\mathrm{CON}(P<0.05)$ in evening.

$\S \mathrm{MDD}<\mathrm{CFS}, \mathrm{CON}(P<0.05)$ in morning and evening.

- Group by time interaction significant but no statistically significant post hoc differences in diurnal change between groups.

Table 6. Mean of three maximum voluntary contractions in right and left hands (mean (S.D.)) morning and evening in CFS, MDD and healthy control subjects (CON)

\begin{tabular}{|c|c|c|c|c|c|c|}
\hline Right hand & $\begin{array}{l}\text { a.m. } \\
\text { p.m. }\end{array}$ & $\begin{array}{l}24 \cdot 3(12 \cdot 4) \\
25 \cdot 7(13 \cdot 6)\end{array}$ & $\begin{array}{l}20 \cdot 6(11 \cdot 5) \\
25 \cdot 2(10 \cdot 8)\end{array}$ & $\begin{array}{l}35 \cdot 8(9 \cdot 2) \\
35 \cdot 2(8 \cdot 4)\end{array}$ & $\begin{array}{l}5 \cdot 9 \\
9 \cdot 4 \\
5 \cdot 8\end{array}$ & $\begin{array}{l}0.005^{*} \\
0.003 \\
0.005\end{array}$ \\
\hline
\end{tabular}

* CFS, MDD $<$ CON $(P<0.05)$ in morning and CFS $<$ CON $(P<0.05)$ in evening.

$\dagger \mathrm{CFS}, \mathrm{MDD}<\mathrm{CON}(P<0.05)$ in morning and evening.

$\$$ Greater increase $(P<0.05)$ morning to evening in MDD than CON.

lower on PASAT 2 as compared to $4 \mathrm{~s}$-but these differences were not statistically significant on testing with paired $t$ tests). This generally poorer performance is also evident in the results from those tests that were given to CFS and healthy control groups in both the morning and evening (see Table 4). CFS subjects had statistically significantly slower reaction times, attributable to movement rather than reaction latency, at both testing times. The results of the digit span backwards test show the predicted differential diurnal pattern of worsening in CFS with improvement in healthy control groups - although the scores themselves do not generally show a statistically significantly deficit in CFS and none of the other tests in this section show diurnal worsening in CFS.

Table 5 shows the results of the tests specifically employed to test our diurnal variation hypothesis - which was not confirmed. Most test results improved, although not to a statistically significant extent, from morning to evening in all three groups. Patients with MDD tended to do worst on all tests at both time points. The only statistically significant group by time interaction is on the digit symbol 
substitution test, but post hoc testing did not reveal any statistically significant between group diurnal changes.

\section{Motor tests}

The results from the sustained hand grip tests are shown in Table 4. CFS patients were able to sustain a $10 \mathrm{~kg}$ contraction for less time than the controls in both the morning and evening, and reported greater subjective effort, but these differences were only statistically significant in the evening and the group by time interactions were non-significant.

The mean of three maximal contractions in the right and left hands of all three subject groups are shown in Table 6. The CFS patients' mean scores are very similar to those of the MDD patients, being approximately 25-30\% lower than in healthy controls in both hands at both time points in both groups. Motor performance tended to improve from morning to evening in CFS, as in MDD, but worsen in healthy controls; although the group by time interaction effect is only significant for a greater improvement in MDD than the healthy control group $(P<0.05)$ for the right (dominant) hand.

\section{Controlling for medication status in CFS}

All the above neurobiological variables $(N=42)$ were compared between CFS subjects on $(N=16)$ and off $(N=14)$ medication. Although two statistically significant differences $(P<0.05)$ could have occurred by chance alone, no such differences were found. Concomitant medication is therefore unlikely to explain the between group differences described above.

\section{DISCUSSION}

\section{Main findings}

We report the results from a detailed study of motor and cognitive function in CFS as compared with both depressed and healthy control groups. Patients with CFS and MDD reported similar levels of fatigue and showed similarly large decrements on maximal voluntary contractions. The MDD group had a significantly greater burden of depressive symptoms and more obviously impaired cognitive performance. Patients with CFS do have neuropsychological deficits, but these are subtle and most apparent when information processing demands are highest or after fatiguing exercise (Blackwood et al.
1998). We found only limited evidence of differential diurnal effects on cognitive and motor function in CFS and MDD.

\section{Limitations}

We recruited some of the CFS subjects from a local self-help group, which may have introduced bias, for example to severity and chronicity. However, there is an approximate $50 \%$ overlap in the local membership and hospital out-patient attenders and any bias would probably have reduced differences between CFS and MDD subjects. Our recruitment strategy means that our results apply to those with CFS as well as to those patients who regard themselves as suffering from ' $\mathrm{ME}$ '. It would have been informative to have a group of CFS subjects with depression, but practical considerations dictated our approach. Including medicated CFS subjects, who were usually taking antidepressants for previous depression or current symptomatic relief (of a possible subclinical depression), means that our results are potentially confounded by medication effects (although we did not find any), but also makes them applicable to the majority of CFS patients with co-morbid psychiatric symptoms. Most of our depressed subjects were medicated, as they had presented for treatment, and it is possible that sedative or anticholinergic effects worsened test performance - although the benefits of treating depression probably outweigh any adverse effects in MDD patients (Calev et al. 1986).

We are limited in the comparisons that can be made of cognitive function across the three subject groups as the MDD patients only completed some of the tests. However, the results of the AVLT and DSST demonstrated pronounced psychomotor and memory deficits in MDD, which were greater than those in CFS. Although we found some of the predicted differential effects of diurnal variation in CFS and MDD as compared to controls, the effects were unimpressive and the MDD subjects were specifically recruited to have diurnal variation in their symptoms, whereas the CFS subjects were not.

\section{Cognitive function}

We report several statistically significant differences in neuropsychological performance between CFS and healthy control subjects, on: 
verbal fluency, CANTAB reaction time, psychomotor speed (DSST) and AVLT measures of immediate recall and recognition. These findings are very much in keeping with previous reports, which have also revealed objective evidence for impairments in verbal fluency (Krupp et al. 1994) and other executive tasks (Grafman et al. 1993; Ray et al. 1993; Wood et al. 1994); reaction time (Smith et al. 1996; Marshall et al. 1997; Vollmer-Conna et al. 1997); psychomotor speed (Smith et al. 1996; Michiels et al. 1997); and in various measures of attention and memory (Grafman et al. 1993; McDonald et al. 1993; Sandman et al. 1993; Krupp et al. 1994; Schmaling et al. 1994; Cope et al. 1995; DeLuca et al. 1995; Marcel et al. 1996; Smith et al. 1996; Marshall et al. 1997; Wearden \& Appleby, 1997; Johnson et al. 1998; Michiels et al. 1998). The effects are modest and show little differential impairment on different test categories. A parsimonious explanation is that of a generalized impairment in information processing, perhaps attributable to low arousal or, given that the slower reaction times in our CFS subjects were attributable to movement rather than reaction latency, a difficulty in the execution of activity.

We found some statistically significantly greater impairments in MDD compared with CFS subjects, on measures of psychomotor speed (DSST) and memory. These results differ from those of the few previous comparisons, which have failed to find such differences (Schmaling et al. 1994; Cope et al. 1995; DeLuca et al. 1995; Marshall et al. 1997; Vollmer-Conna et al. 1997). We suspect that different outcomes depend upon the exclusion of CFS patients with a current depressive illness and the inclusion of more severe MDD cases. The similar degree of fatigue and motor impairment in our CFS and MDD patients suggests that the cognitive differences are not simply attributable to nonspecific effects of illness severity.

\section{Motor function}

The shorter length of time that CFS subjects sustained a hand grip in the right (dominant) hand than healthy controls has not been previously reported, as far as we are aware. Although we cannot definitely state that these differences are not attributable to loss of muscle power (e.g. due to disuse), isometric muscle strength is generally normal in CFS (Lloyd et al.
1991; Kent-Braun et al. 1993; Blackwood et al. 1998) and it is parsimonious to link these results to the complementary findings of increased effort perception in these previous studies. The mean of three maximal voluntary contractions was strikingly lower in CFS subjects than in the healthy controls, being similar to those with MDD. Thus, patients with CFS have motor problems that are as severe as those found in MDD but a lesser degree of cognitive impairment.

\section{Diurnal variation}

There is only partial support for our differential diurnal variation hypothesis - i.e. improvement in MDD and worsening in CFS as the day wears on. The MDD patients' performances on cognitive and motor tasks do tend to objectively improve, as other have previously shown (Moffoot et al. 1994; Porterfield et al. 1997), but these improvements are not statistically different from those in CFS patients. There is certainly no consistent diurnal worsening in function in CFS as compared to MDD. Nonetheless, the fact that symptoms and task performance in CFS do not generally fluctuate diurnally, whereas they clearly can in MDD, suggests that there are neurobiological differences between the disorders despite many similarities in aetiological factors and symptoms. This is unlikely to be simply a matter of severity as our subjects with CFS performed as poorly as our MD subjects on many measures.

\section{Implications}

We have recently advanced an hypothesis that CFS may be primarily attributable to a failure in effort mobilization that is most evident on 'effortful' or controlled motor or cognitive activity (Lawrie et al. 1997b). Others have had similar ideas (Joyce et al. 1996). On self-rating of fatigue, and on objective measures of motor performance, patients with CFS and severe depressive illness were similar. Given the powerful evidence that retardation of motor function is a key feature of severe depressive illness (Parker \& Hadzi-Pavlovic, 1996), this emphasis on motor performance is something that the conditions share. Why they do and what the underlying mechanisms are remain uncertain.

In regard to cognitive function, however, the two groups of patients studied in this report 
show clear differences that suggested a more profound impairment of function in patients with severe depression. CFS subjects did tend to perform relatively more poorly than healthy controls on 'harder' tasks with greater demands on information processing capacity. Effortful cognition is also compromised in MDD (Cohen et al. 1982; Austin et al. 1992; Lawrie et al. $1997 \mathrm{~b}$ ), but the impairments at rest are much greater. CFS and MDD patients differ importantly in the impact of an exercise stressor upon neuropsychological performance (Blackwood et al. 1998).

Our observations accord with early reports of objectively mild but subjectively severe cognitive deficits in CFS (Millon et al. 1989; Altay et al. 1990; Ray et al. 1993). These were often interpreted as evidence of exaggerated complaints in CFS, as were early reports of increased effort perception, and usually attributed to personality difficulties (Buckley et al. 1999). To us, it is just as likely that subjective reports reflect processing requirements and objectively impaired neuropsychological function in CFS.

In this report, there are important similarities and differences between CFS and MDD, as we have found in studies of neuroendocrine function (MacHale et al. 1998) and with Single Photon Emission Tomography (MacHale et al. 2000). CFS and MDD may have similar provoking factors and an important overlap in the motor domain. If motor disturbance is primary, as CFS patients typically regard it, we still do not understand why that has different consequences for cognition in CFS from that in severe depression. Alternatively, psychomotor retardation in MDD may be associated with a less reversible impairment of cognitive function than that in CFS. Fatigue needs to be studied in a range of depressed patients before we can be confident that the crossover of impairment from the motor to the cognitive domain is as specific to CFS as it currently appears to be.

We thank the Scottish Office for financial support, Cathy Murray for technical assistance, local physicians for help in recruiting patients, and the subjects themselves for their time and interest in the study.

\section{REFERENCES}

Altay, H. T., Abbey, S. E., Toner, B. B., Salit, I. E., Brooker, H. \& Garfinkel, P. E. (1990). The neuropsychological dimensions of postinfectious neuromyasthenia (chronic fatigue syndrome): a preliminary report. International Journal of Psychiatry in Medicine 20, 141-149.

American Psychiatric Association, (1987). Diagnostic and Statistical Manual of Mental Disorders 3rd edn-revised (DSM-III-R). APA: Washington, DC.

Austin, M. P., Ross, M., Murray, C., O'Carroll, R. E., Ebmeier, K. P. \& Goodwin, G. M. (1992). Cognitive function in major depression. Journal of Affective Disorders 25, 21-30.

Behan, P. O. \& Bakheit, A. M. O. (1991). Clinical spectrum of the postviral fatigue syndrome. British Medical Bulletin 47, 793-808. Benton, A. L. \& Hamsher, K. (1978). Multilingual Asphasia Examination. University of Iowa Hospitals: Iowa.

Blackwood, S., MacHale, S. M., Power, M., Goodwin, G. M. \& Lawrie, S. M. (1998). The effects of exercise on cognitive and motor function in chronic fatigue syndrome and depression. Journal of Neurology, Neurosurgery and Psychiatry 65, 541-546.

Borg, G. A. V. (1982). Psychophysical basis of perceived exertion. Medical Science and Sports Exercise 14, 377-381.

Brittain, J. L., La Marche, J. A. \& Reeder, K. P. (1991). Effects of age and IQ on PASAT performance. Clinical Neuropsychologist $\mathbf{5}$, 163-175.

Buckley, L., MacHale, S. M., Cavanagh, J. T. O., Sharpe, M., Deary, I. J. \& Lawrie, S. M. (1999). Personality dimensions in chronic fatigue syndrome and depression. Journal of Psychosomatic Research 46, 395-400.

Calev, A., Korin, Y., Shapira, B., Kugelmass, S. \& Lerer, B. (1986). Verbal and non-verbal recall by depressed and euthymic affective patients. Psychological Medicine 16, 789-794.

Chalder, T., Berelowitz, G., Pawlikowska, T., Watta, L., Wessely, S., Wright, D. \& Wallace, E. P. (1993). Development of a fatigue scale. Journal of Psychosomatic Research 37, 147-153.

Cohen, R. M., Weingartner, H., Smallberg, S. A., Pickar, D. \& Murphy, D. L. (1982). Effort and cognition in depression. Archives of General Psychiatry 39, 593-597.

Cope, H., Pernet, A., Kendall, B. \& David, A. (1995). Cognitive functioning and magnetic resonance imaging in chronic fatigue. British Journal of Psychiatry 167, 86-94.

Crawford, J. R., Stewart, L. E. \& Moore, J. W. (1989). Demonstration of savings on the AVLT and development of a parallel form. Journal of Clinical and Experimental Neuropsychology 11, 975-981.

David, A. S. (1991). Postviral fatigue syndrome and psychiatry. British Medical Bulletin 46, 966-988.

Delis, D. C., Kramer, J. H. \& Kaplan, E. (1987). California Verbal Learning Test: Adult Version. The Psychological Corporation: San Antonio, TX.

DeLuca, J., Johnson, S. K., Beldowitz, D. \& Natelson, B. H. (1995). Neuropsychological impairments in chronic fatigue syndrome, multiple sclerosis, and depression. Journal of Neurology Neurosurgery and Psychiatry 58, 38-43.

Endicott, J. \& Spitzer, R. L. (1978). A diagnostic interview - the schedule for affective disorders and schizophrenia. Archives of General Psychiatry 35, 837-884.

Fukuda, K., Straus, S. E., Hickie, I., Sharpe, M. C., Dobbins, J. G. \& Komaroff, A. (1994). The chronic fatigue syndrome: approach to its definition and study. Annals of Internal Medicine 121, 953-959.

Grafman, J., Schwartz, V., Dale, J. K., Scheffers, M., Houser, C. \& Straus, S. E. (1993). Analysis of neuropsychological functioning in patients with chronic fatigue syndrome. Journal of Neurology Neurosurgery and Psychiatry 56, 684-689.

Hamilton, M. (1960). A rating scale for depression. British Journal of Medical Psychology 32, 50-55.

Johnson, S. K., DeLuca, J., Diamond, B. J. \& Natelson, B. H. (1998). Memory dysfunction in fatiguing illness: examining interference and distraction in short-term memory. Cognitive Neuropsychiatry 3, 269-285.

Joyce, E., Blumenthal, S. \& Wessely, S. (1996). Memory, attention and executive function in chronic fatigue syndrome. Journal of Neurology Neurosurgery and Psychiatry 60, 495-503.

Kaplan, E. F., Goodglass, H. \& Weintraub, S. (1983). The Boston Naming Test. Lea \& Fabiger: Philadelphia. 
Kendell, R. E. (1991). Chronic fatigue, viruses and depression. Lancet 337, 160-162.

Kent-Braun, J. A., Sharma, K. R., Weiner, M-W., Massie, B. \& Miller, R. G. (1993). Central basis of muscle fatigue in chronic fatigue syndrome. Neurology 43, 125-131.

Krupp, L. B., Sliwinski, M., Masur, D. M., Friedberg, F. \& Coyle, P. K. (1994). Cognitive functioning and depression in patients with chronic fatigue syndrome and multiple sclerosis. Archives of Newrology 51, 705-710.

Lawrie, S. M., Manders, D. N., Geddes, J. R. \& Pelosi, A. J. (1997a). A population-based incidence study of chronic fatigue. Psychological Medicine 27, 343-353.

Lawrie, S. M., MacHale, S. M., Power, M. J. \& Goodwin, G. M. $(1997 b)$. Is the chronic fatigue syndrome best understood as a primary disturbance of the sense of effort? Psychological Medicine 27, 995-999.

Lezak, M. D. (1983). Neuropsychological Assessment. Oxford University Press: Oxford.

Lloyd, A. R., Gandevia, S. C. \& Hales, J. P. (1991). Muscle performance, voluntary activation, twitch properties and perceived effort in normal subjects and patients with chronic fatigue syndrome. Brain 114, 85-98.

McDonald, E., Cope, H. \& David, A. (1993). Cognitive impairment in patients with chronic fatigue: a preliminary study. Journal of Neurology Neurosurgery and Psychiatry 56, 812-815.

MacHale, S. M., Cavanagh, J. T. O., Bennie, J., Carroll, S., Goodwin, G. M. \& Lawrie, S. M. (1998). Diurnal variation of adrenocortical activity in chronic fatigue syndrome. Neuropsychobiology $\mathbf{3 8}$, 213-217.

MacHale, S. M., Lawrie, S. M., Cavanagh, J. T. O., Glabus, M. F., Murray, C. L., Goodwin, G. M. \& Ebmeier, K. P. (2000). Cerebral perfusion in CFS and depression. British Journal of Psychiatry (in the press).

Marcel, B., Komaroff, A. L., Fagioli, L. R., Kornish, R. J. \& Albert, M. S. (1996). Cognitive deficits in patients with chronic fatigue syndrome. Biological Psychiatry 40, 535-541.

Marshall, P. S., Forstot, M., Callies, A., Peterson, P. K. \& Schenck, C. H. (1997). Cognitive slowing and working memory difficulties in chronic fatigue syndrome. Psychosomatic Medicine 59, 58-66.

Michiels, V., Cluydts, R. \& Fischler, B. (1998). Attention and verbal learning in patients with chronic fatigue syndrome. Journal of the International Psychological Society 4, 456-466.

Millon, C., Salvato, F., Blaney, N., Morgan, R., Mantero-Atienza, E., Klimas, N. \& Fletcher, M. A. (1989). A psychological assessment of chronic fatigue syndrome/chronic Epstein Barr virus patients. Psychological Health 3, 131-141.

Moffoot, A. P. R., O'Carroll, R. E., Bennie, J., Carroll, S., Ebmeier, K. P. \& Goodwin, G. M (1994). Diurnal variation of mood and neuropsychological function in major depression with melancholia. Journal of Affective Disorders 32, 257-269.

Nelson, H. \& Willison, J. (1991). National Adult Reading Test (2nd $e d n)$. NFER-Nelson: Windsor.

Parker, G. \& Hadzi-Pavlovic, D. (1996). Melancholia: A Disorder of Movement and Mood. Cambridge University Press: Cambridge.

Porterfield, T., Cook, M., Deary, I. \& Ebmeier, K. P. (1997)

Neuropsychological function and diurnal variation in depression. Journal of Clinical and Experimental Neuropsychology 19, 906-913.
Randt, C. T. \& Brown, E. R. (1983). Randt Memory Test. Life Sciences Associates: New York.

Ray, C., Phillips, L. \& Weir, W. R. C. (1993). Quality of attention in chronic fatigue syndrome: subjective reports of everyday attention and cognitive difficulty, and performance on tasks of focussed attention. British Journal of Clinical Psychology 32, 357-364.

Reitan, R. M. (1958). Validity of the trail making test as an indication of organic brain damage. Perceptual and Motor Skills $\mathbf{8}$, 271-276.

Rey, A. (1964). L'examen clinique en psychologie. Presses Universitaires de France: Paris.

Riccio, M., Thompson, C., Wilson, B., Morgan, D. J. R. \& Lant, A. F. (1992). Neuropsychological and psychiatric abnormalities in myalgic encephalomyelitis: a preliminary report. British Journal of Clinical Psychology 31, 111-120.

Riley, M. S., O'Brien, C. J., McCluskey, D. R., Bell, N. P. \& Nicholls, D. P. (1990). Aerobic work capacity in patients with chronic fatigue syndrome. British Medical Journal 301, 953-956.

Sahakian, B. J. \& Owen, A. M. (1992). Computerised assessment in neuropsychiatry using CANTAB: discussion paper. Journal of the Royal Society of Medicine 85, 399-402.

Sandman, C. A., Barron, J. L., Nackoul, K., Goldstein, J. \& Fidler, F. (1993). Memory deficits associated with chronic fatigue immune dysfunction syndrome. Biological Psychiatry 33, 618-623.

Schmaling, K. B., DiClementi, J. D., Cullum, C. M. \& Jones, J. F. (1994). Cognitive functioning in chronic fatigue syndrome and depression: a preliminary comparison. Psychosomatic Medicine 56, 383-388

Smith, A., Pollock, J., Thomas, M., Llewelyn, M. \& Borysiewicz, L. (1996). The relationship between subjective ratings of sleep and mental functioning in healthy subjects and patients with chronic fatigue syndrome. Human Psychopharmacology 11, 161-167.

Stokes, M. J., Cooper, R. G. \& Edwards, R. H. T. (1988). Normal muscle strength and fatiguability in patients with effort syndromes. British Medical Journal 297, 1014-1017.

Vollmer-Conna, U., Wakefield, D., Lloyd, A., Hickie, I., Lemon, J., Bird, K. D. \& Westbrook, R. F. (1997). Cognitive deficits in patients suffering from chronic fatigue syndrome, acute infective illness or depression. British Journal of Psychiatry 171, 377-381.

Von Zerssen, D., Strian, F. \& Schwarz, D. (1974). Evaluation of depressive states, especially in longitudinal studies. In Psychological Measurements in Psychopharmacology (ed. P. Pichot), pp. 189-202. Karger: Paris.

Ware, J. E. \& Sherbourne, C. D. (1992). The Medical Outcomes Study 36-item short form health survey (SF-36): I. Conceptual framework and item selection. Medical Care 30, 473-483.

Wearden, A. \& Appleby, L. (1997). Cognitive performance and complaints of cognitive impairment in chronic fatigue syndrome. Psychological Medicine 27, 81-90.

Wechsler, D. (1981). Manual for the Wechsler Adult Intelligence Scale - Revised. Psychological Corporation: New York.

Wood, G. C., Bentall, R. P., Gopfert, M., Dewey, M. E. \& Edwards, R. H. (1994). The differential response of chronic fatigue, neurotic and muscular dystrophy patients to experimental psychological stress. Psychological Medicine 24, 357-364. 